\title{
Proceedings of the 121st Meeting of the Society of British Neurological Surgeons held jointly with the Deutsche Gesselschaft für Neurochirurgie, Hull, 23-26 September 1992
}

LASER NEUROSURGERY IN THE TREATMENT OF GLIOMAS

G Brocklehurst, Hull

A total of 277 gliomas had been analysed in relationship to the use of laser technique:

\begin{tabular}{lcc}
\hline & Lasered & Not lasered \\
\hline Number & 188 & 89 \\
Av Opn Time (hr) & $2 \cdot 9$ & $2 \cdot 5$ \\
Av Blood Repl (1) & $0 \cdot 2$ & $0 \cdot 1$ \\
Mortality (at 1 month) & 22 & 9 \\
Post-op WHO grade & $2 \cdot 5$ & $2 \cdot 7$ \\
Death \% (recurr): & & \\
1 month & $11 \cdot 8$ & $13 \cdot 5$ \\
3 months & $14 \cdot 1$ & $24 \cdot 1$ \\
6 months & $24 \cdot 6$ & $43 \cdot 7$ \\
12 months & $46 \cdot 7$ & $67 \cdot 9$ \\
18 months & $56 \cdot 4$ & $82 \cdot 1$ \\
24 months & $60 \cdot 3$ & $88 \cdot 1$ \\
36 months & $67 \cdot 3$ & $90 \cdot 4$ \\
48 months & $75 \cdot 3$ & $91 \cdot 6$ \\
60 months & $80 \cdot 1$ & $92 \cdot 8$ \\
120 months & 95.9 & 96.3 \\
\hline
\end{tabular}

Analysis of degree of malignancy, tumour site, and age revealed that the laser made no difference to ultimate outcome in the Grade 3 and 4 gliomas, but favourably influenced survival in the lower grade tumours, particularly those that were relatively inaccessible.

FRAMELESS STEREOTAXY: PRELIMINARY EXPERIENCE WITH A PREOPERATTVE THREE DIMENSIONAL IMAGE GUIDED SURGICAL TOOL, THE ISG VIEWING WAND

DR Sandeman, R Nelson, HB Coakham. Bristol

Stereotactic techniques have limited application to general neurosurgery because they are time consuming, require the application of an external frame, per operative imaging and only provide point source localisation within the cranium. Despite recent advances in the quality of neuro imaging there have not been any further developments in image directed surgical techniques until now. The authors report their preliminary experiences with the ISG Viewing Wand. This is a surgical guidance tool where the tip of a mechanical arm is registered to a preoperative three dimensional reconstruction of a patient's MRI or CT scan. The wand can then be used as a pointer to direct the surgeon to any point within the cranial cavity peroperatively. Using the Allegro Three Dimensional (3D) Imaging System a 3D reconstruction of the patient's preoperative image is built up. After fixing the head in a three pin headrest the viewing wand is then attached to the headrest. The tip of the wand is then positioned on anatomical features of the patient's skin that are recognisable on the $3 \mathrm{D}$ image in order to register the wand position to the patient's image. Once this process is complete as the wand is moved so its position relative to the preoperative image is shown on the screen. The wand had been used in 22 cases-13 cases of intrinsic brain tumours, 6 epilepsy cases, 2 skull based tumours and one vascular case, where the wand was used to locate a very distal middle cerebral artery aneurysm. This preliminary experience suggests that this technique represents a major advance in image directed neurosurgery, as it adds an extra dimension to the safety and accuracy of standard neurosurgical procedures.

INTRAOPERATIVE LOCALISATION, GRADING AND MARGIN IDENTIFICATION OF BRAIN TUMOURS USING OPTICAL IMAGING H Haglund, MS Berger, AM Spence, DW Hochman. Seattle, USA

Current intraoperative techniques do no allow for precise tumour localisation once the resection starts nor do they give accurate, detailed information regarding tumour margins. A new intraoperative technique has been developed using optical imaging which may allow tumour grading, localisation and identification of margins at the time of surgery. Using a high-resolution charge coupled device television camera attached to the operating microscope, images were collected before and after intravenous injection of indocyanine green dye. In a rat glioma model, images of the normal hemisphere and the hemisphere containing tumour showed rapid entrance of the dye into both hemispheres (1-2 second post injection); however, while the tumour tissue continued to sequester the dye, the normal tissue cleared the dye within 1 minute. After removal of the visible tumour, biopsies were taken from areas positive and negative for tumour by optical imaging. The optical imaging was $100 \%$ sensitive (15/15) and $89 \%$ specific (17/19) in identifying the tumour margins. Preliminary data from 12 glioma patients had shown optical imaging differences between normal brain and low-grade astrocytomas and accurately identified tumour margins. Two cases were identified as malignant by optical imaging even though preoperative MRI and CT had shown non-contrast-enhancing tumours suggesting low-grade astrocytomas.

DIRECT MEASURMENT OF THE PO DISTRIBUTION IN HUMAN MALIGNANT BRAIN TUMOURS

GS Cruickshank, RP Rampling, W Cowans. Glasgow and Philadelphia, USA

Malignant brain tumours confer a much worse prognosis than other solid tumours. Their growth, as well as their responses to radiotherapy and chemotherapy, may, like other tumours, be influenced by the presence of hypoxic regions. However the phenomenon of hypoxic areas in malignan brain tumours has been challenged. ${ }^{1}$ Low $\mathrm{pO}_{2}(<2.5 \mathrm{~mm} \mathrm{Hg})$ areas provide a source of radiobiological resistance, whereas $\mathrm{pO}_{2}$ levels less than $10-15 \mathrm{~mm} \mathrm{Hg}$ may provide conditions for the activation of the new bioreductive cytotoxic agents.

In open craniotomies, the fine needle Eppendorf- $\mathrm{pO}_{2}$-Histograph polarography system had been used to investigate the tissue oxygen tension in and around tumours in 18 patients.

Peritumoural brain: multiple track measurements were made in peritumoural areas in 8 patients. Pooled $\mathrm{pO}_{2}$ values plotted as frequency histograms showed lower levels than expected (median $10.7 \mathrm{~mm} \mathrm{Hg}, 47.5 \%$ of values below $10 \mathrm{~mm} \mathrm{Hg}$ ) illustrating a marked positive (left) skew. Tumour decompression shifted the $\mathrm{pO}_{2}$ frequency histogram to the right (median $17.5 \mathrm{~mm} \mathrm{Hg}, 28.1 \%$ of values below $10 \mathrm{~mm} \mathrm{Hg}$ ) suggesting improved tissue oxygenation, possibly related to improved blood supply.

Malignant brain tumours: The presence of low $\mathrm{pO}_{2}$ values $(<2.5 \mathrm{~mm} \mathrm{Hg})$ was confirmed in nine out of ten patients with astrocytomas, and one with an oligodendrocytoma. In glioblastomas (median 9.6 $\mathrm{mm} \mathrm{Hg} \mathrm{N}=6$ ) and anaplastic astrocytomas with no necrosis (median $15.3 \mathrm{~mm} \mathrm{Hg}$ $N=2$ ) the number of values less than 15 $\mathrm{mmHg}$ was on average around $50 \%$ whereas values below $15 \mathrm{~mm} \mathrm{Hg}$ occurred more frequently in the metastases. The incidence of low $\mathrm{pO}_{2}$ values in these intracranial tumours was much higher than that recorded by others with this technique in extracranial tumours. ${ }^{2}$

These results suggest that a high proportion of malignant brain tumours contain areas of low oxygenation. These areas are present in greater fractions than have been recorded in other solid tumours, but may also offer an environment for bioreductive cytotoxic drug activation.

1 Brooks D J, Beaney R P, Thomas D G T Seminars in Oncology 1988;13:83-93.

2 Vaupel P, Schlenger K, Knoop C, Hockel M. Cancer Research 1991;51:3316-22.

INFORMATION TECHNOLOGY: HOW FAR CAN IT BE TAKEN IN THE RUNNING OF A NEUROSURGICAL UNIT? EXPERIENCE WITH THE ICS “CLINICS" SYSTEM

PO Byrne, JR Bartlett, RW Gullan. Brook Hospital, London

The Working Party of the SBNS looking 
into audit and information technology, at the beginning of 1990 , recommended the ICS "Clinics" system as one of the most suitable available. At the Brook Hospital, the South East Thames Regional Neurosurgical Unit, which covers a population of approximately 1.7 million, the ICS system was adopted as a complete substitute for the day to day administrative aspects of patient management. A networked system had been fully operational for 21 months and 3614 patients had been registered. The system was used comprehensively to carry out the following functions: full registration of demographic and referral details, all outpatient booking and follow up appointments (5628 to date), generation of all outpatient appointment and admission letters, all outpatient letters and other correspondence about patients, generation of operating lists, discharge summaries (2166 to date) and provision of all data for Korner returns.

This work was done exclusively by the three personal secretaries to each consultant neurosurgeon and their junior medical staff, without the need for any other administrative bureaucracy.

The costs of a fully networked system for the department had been in the region of $£ 60,000$. This was made up of the cost of the software and its licence(s); and the hardware, consisted of a 386sx 150MB PC as File Server, four $28640 \mathrm{MB}$ PC workstations networked with "Novell Netware", a Laser printer, an independent tape streamer for backup, a modem and a backup power supply. This cost was fully justified because of the enormous increases in efficiency that had been created, and was low compared to other management systems with much less potential. To create such a management mechanism was not without difficulty, however, and an extraordinary amount of adaption and meticulous "fine tuning" had been required. The system is being expanded for financial management and advanced statistical audit.

INTRACRANIAL VOLUME, INTRACRANIAL PRESSURE AND UPPER AIRWAY OBSTRUCTION IN CHIIDREN WITH CRANIOSYNOSTOSIS W Harkness, D Gault, B Jones, U Andar, R Hayward. Great Ormond Street, London

The association between craniosynostosis and raised intracranial pressure is well recognised and early detection of raised pressure is one of the factors leading to early surgery for these conditions. Two hypotheses to explain the raised pressure had been examined: restricted growth consequent upon premature suture fusion and upper airway obstruction. Firstly, a series of 41 patients with craniosynostosis were studied with close cut CT scans to allow estimation of intracranial volume and subsequently the intracranial pressure was measured with the Camino pressure monitoring system. Intracranial volume was of no predictive value for raised ICP. Secondly, sleep studies of ICP, arterial oxygen saturation and respiratory patterns had revealed evidence of airways obstruction in a minority of patients during rapid eye movement sleep associated with episodes of raised ICP. Much discussion ensued as to the timing of surgical correction of maxillary hypoplasia given the poor long term results if performed too early.
TRANSCRANIAL DOPPLER ULTRASOUND IN CRANIOSYNOSTOSIS.

J B Iqbal, A D Hockley, M J C Wake, J H Goldin. Birmingham

Modern craniofacial techniques produce improved results in craniosynostosis, as assessed by radiological and pressure studies but changes in cerebral haemodynamics following surgery are documented less well. Ten patients (age range 3 to 36 months) were studied using the Scimed PCDOP 842 unit and a $2 \mathrm{MHz}$ probe via the temporal and frontal "windows" of the skull. Doppler parameters were recorded pre, intra and post-operatively.

Flow velocities (systolic and mean) increased in 6 patients following surgery with a fall in pulsatility index in five patients. There were wide individual variations noted in flow velocity values between patients and the need for control studies highlighted.

NEW INSTRUMENTATION FOR THE ASSEMBLY OF SHUNT SYSTEMS BY A NON-TOUCH TECHNIQUE

\section{R Ashpole. Cambridge}

Access to the ventricular system by whichever of the many systems available runs the risk of infection. Reported rates vary from $2 \cdot 4 \%-52 \%$ and are related to site of shunt, hygienic precautions, patient's age, number of revisions, prophylactic antibiotics, surgical technique and experience. As with any procedure involving the insertion of prosthetic material, a non-touch technique is widely advocated. Most of these components are small, however, and assembling them wet, whilst wearing surgical gloves, can be difficult, leading to delay and breakdown of the non-touch technique. In practice there are no instruments available to assemble this variety of components, and the reality is that a shunt is often assembled using a combination of perished rubber-covered forceps, fingers and wet swabs. A purpose designed system of instrumentation was described which could accommodate all the shunt and access devices in the PS Medical range and could easily be adapted to other systems. It consisted of a valve holding block and a series of ratchet and thumb forceps to manipulate and connect the various components. Since their introduction eighteen months ago they had been used successfully in four neurosurgical centres in the UK and in the USA. Final prototypes were now complete and the set had entered commercial production.

TRIGEMINAL NEURALGIA TREATED BY MICROVASCULAR DECOMPRESSION: A LONG TERM FOLLOW UP STUDY

ND Mendoza, RD Illingworth. Charing Cross Hospital, London

The outcome of 133 patients, with 134 episodes of Trigeminal Neuralgia (TGN) was presented. The period of follow up was 15 years to six months, with an average of $5 \cdot 2$ years. Sixty patients had been followed up for more than 5 years.

There were 80 females and 53 males with an average age of onset and duration of symptoms of 48.3 and 7.2 years respectively. The anatomical structures found at oper- ation to be either in contact with or causing compression of the root exit zone were: Artery $72.4 \%$, Artery and Vein $15.7 \%$, Vein $4.5 \%$ and Tumour $4.5 \%$. No abnormality was found in $2.9 \%$ of patients: these patients had partial rhizotomy.

The operative findings were divided into "definite" and "not definite" subgroups. Outcome was evaluated in terms of either recurrence or non-recurrence of pain; recurrence of pain was further subdivided into major recurrence and minor recurrence. Ninety five patients $(70.9 \%)$ had remained pain free whilst 18 patients $(13.4 \%)$ and 21 patients $(15 \cdot 7 \%)$ had a major and minor recurrence respectively. A total of $90 \%$ of patients who developed recurrent TGN did so within two years with only 1 patient of 75 who had been followed for more than 4 years developing recurrent pain.

Recurrence of TGN was statistically more likely to occur where there were indefinite operative findings or the age of onset was less than 35 years. There was no correlation with duration of symptoms. These findings differ from other published studies which had demonstrated a continuous annual recurrence rate of about 2 to $5 \% .^{12}$

\section{Burchiel K J, Clarke H, Haglund M, Loeser J D. $\mathcal{F}$ Neurosurg 1988;69:35-38. \\ 2 Bederson J B, Wilson C B. \& Neurosurg 1989,71:359-67.}

CONTINUOUS MONITORING OF INTRACRANIAL BUFFERING CAPACITY IN HEAD INJURED PATIENTS

DJ Price, M Czosnyka, M Williamson. Wakefield and Cambridge

The monitoring of ICP has been well established as a detection aid for expanding contusions and haematomas in those head injured patients requiring elective ventilation. The significance of variations of ICP in those patients without CT evidence of such surgical complications is less easy to interpret. To prevent unnecessary ischaemia, more information is needed by monitoring both the volume buffering capacity and the state of autoregulation.

The results of computerised monitoring of 80 head injured patients were analysed. One minute averaged values were recorded of intracranial, systematic arterial, cerebral perfusion pressures (ICP, SAP, CPP) amplitude of the fundamental component of intracranial pressure pulse wave and the short term correlation coefficient between that amplitude and ICP (RAP). The analysis revealed that reductions of CPP to a critical level of $40 \mathrm{mmHg}$ were statistically more often caused by decreases in SAP than to increases in ICP. In 2000 monitored hours, such severe hypoperfusion occurred for $5 \%$ of the time and a CPP below $60 \mathrm{mmHg}$ occurred for $24 \%$ of that time. The coefficient RAP, representing buffering capacity, correlated more strongly with a low CPP than a high ICP. The authors concluded that the provision of an adequate CPP, particularly by increasing SAP, was essential to provide better buffering capacity.

ASSESSING THE BURDEN OF SECONDARY INSULTS IN HEAD INJURED PATIENTS DURING INTENSIVE CARE

PA Jones, PJD Andrews, S Midgley, SI Anderson, IR Piper, J Tocher, A Houseley, 
J Corrie, J Slattery, M Dearden, JD Miller. Edinburgh

Effects of primary traumatic brain damage may be compounded by secondary pathophysiological insults which can occur soon after trauma, during transfer to hospital or during subsequent treatment of the head injured patient. Secondary insults found in 100 adult head injured patients during intensive care, using a novel computerised data collection system which could record up to 17 physiological variables, minute-byminute, were recorded. Verified values falling outside threshold limits for at least 5 minutes, were described by the Edinburgh University Secondary Insult Grades, and insult duration and number were analysed.

Insults were found in $92 \%$ of patients, and occurred in all severities of head trauma, at all ages, and at every level of Injury Severity Score (ISS). An extremely high occurrence of insults was recorded, although the majority $(77 \%)$ were at Grade 1 level, representing $84 \%$ of total insult duration. Short duration insults were common. When secondary insults are carefully sought after, a much greater incidence will be detected than previous studies have indicated. A subset of 55 patients' data, who had 8 channels monitored (Intracranial Pressure, Arterial hypo- and hypertension, Cerebral Perfusion (CPP), Hypoxaemia, Pyrexia, Brady- and Tachycardia) were analysed using logistic regression to determine the effects of age, admission Glasgow Coma Sumscore, ISS and insult duration on mortality. The most significant predictor was CPP insult duration $(p=0.0030)$, followed by hypoxaemic insults $(p=0.0129)$, and Glasgow Coma Sumscore on admission $(p=0.0247)$.

NIMOPIDINE IN SEVERE HEAD INJURY.

GM Teasdale, on behalf of the HIT II Study Group. Glasgow

The calcium antagonist Nimodipine has an established place in the prevention of delayed ischaemia after subarachnoid haemorrhage. Secondary ischaemic insults are common in severely head injured patients, many of whom also have subarachnoid haemorrhage. A trial of Nimodipine treatment of head injury (HIT I) ${ }^{1}$ did not show a dramatic significant benefit; the $95 \%$ confidence intervals for the effect of Nimodipine included a relative increase in favourable outcome by $33 \%$ to a decrease by $12 \%$. A second study, HIT II, was conducted involving 19 European units, including 2 in the United Kingdom and 2 in Germany. A total of 852 patients who were not obeying commands within 12 hours of injury were allocated randomly to either placebo or Nimodipine given as an intravenous infusion for 7 days. The 2 groups were well balanced for early prognostic factors; $38 \%$ had craniotomy for haematoma. At 6 months $61 \%$ of the Nimodipine treated patients had made a favourable recovery (moderate or good) and $59 \%$ of the placebo subjects. A secondary analysis of subgroups, specified in advance, showed that patients with subarachnoid haemorrhage on the CT scan had a worse prognosis and that this may be improved by Nimodipine treatment. 1992;110:97-105.
ACUTE SUBDURAL HAEMATOMA IN THE CONSCIOUS PATIENT: OUTCOME WITH INITIAL NON-OPERATIVE MANAGEMENT D Oluoch-Olunya, P Mathew, B Condon, R Bullock. Glasgow

Is non-operative management safe for small post-traumatic acute subdural haematomas, (ASDH) in the conscious patient? How does ASDH progress to a chronic subdura haematoma? The authors retrospectively reviewed all patients presenting to the Neurosurgical Unit over a six year period, with a CT scan diagnosis of acute subdura haematoma. Of 837 patients with ASDH, 23 were conscious and had no other associated intracranial abnormalities, and craniotomy for evacuation was not initially performed. This sample of 23 patients was followed by serial CT scanning and neurological assessments. In 17 of these patients, the ASDH resolved spontaneously, without evidence of damage to the underlying brain as shown by CT or neurological findings. Six subsequently required burr hole drainage of a hypodense liquid subdural haematoma. In each of these patients, haematoma thickness was greater than 10 $\mathrm{mm}$. Haematoma volume was thus significantly larger in the group who came to operation. There was good correlation between increasing midline shift and increase in haematoma thickness seen on serial CT scans in these six patients, suggesting that hemisphere swelling was not occurring.

Certain conscious patients with acute subdural haematomas, less than $10 \mathrm{~mm}$ thick, may be safely managed conservatively but there may be economic implications to be considered.

THE PRESENCE OF TUMOUR NECROSIS FACTOR IN CSF AND PLASMA AFTER SEVERE HEAD INJURY

SA Ross, MI Halliday, GC Campbell, DP Byrnes, BJ Rowlands. Belfast

Tumour necrosis factor (TNF) is a cytokine mediator, produced by activated macrophages, which has important effects on whole-body metabolism and cellular energy flux. As it may explain some of the metabolic derangements after brain trauma, the authors had looked for the expression of TNF after severe head injury. The molecule was assayed, using a highly sensitive ELISA. Samples of plasma and CSF were taken from 50 head injured patients within 24 hours of impact. Control samples were obtained during myelography from 46 patients undergoing investigation of backache. Mean TNF concentrations in plasma from controls and that from injured patients were 1.9 (SD 0.2 ) $\mathrm{pg} / \mathrm{ml}$ and 12.2 (SD $46.0) \mathrm{pg} / \mathrm{ml}$ respectively. Because the distribution of TNF was not normal, the data were logarithmically transformed before using Student's $t$-test to test the difference between geometric means. The difference was $T=2.62, p=0.01$. Mean TNF concentrations in CSF from controls and injured were 0.9 (SD 0) and 4.0 (SD 3.6) $\mathrm{pg} / \mathrm{ml}$ respectively. The difference was significant at $T=7 \cdot 74, \mathrm{p}<0.01$.
THE PLACE OF STEREOTACTIC

RADIOSURGERY (STRS) IN THE MANAGEMENT

OF CEREBROVASCULAR ANOMAIIES

DMC Forster, AA Kemeny. Sheffield

The first five years of stereotactic radiosurgery in Sheffield had been part of the research and development programme with over 700 patients treated. The great majority of patients harboured arteriovenous malformations. Seventy five to $80 \%$ of the high flow malformations had radiation induced thrombo-obliteration following treatment. Suitability and results were dependent on size, site and shape of the lesion. There is an important role for embolisation before STRS. Other less common vascular malformations, such as Vein of Galen malformations, had been treated. In the cost-conscious Health Service there is an increasing pressure on clinicians for managers to choose the most cost-effective method of treatment as well as the safest and best for the patients. In this context STRS compares favourably with open surgery.

EXPERIENCE OF THE ANTERO-LATERAI APPROACH TO PROLAPSED THORACIC DISCS MR Gooding. Hull

In 1980, the author described an anterolateral approach to thoracic disc prolapse at the combined meeting of the French and British Neurological Surgeons. In the present series there were 20 patients, consisting of 11 men (mean age 55) and 9 women (mean age 48), ages ranging from 27 to 80 years with a mean of 52 years. The incidence was approximately 1 case per 1.06 million population per year, correlating well with other authors. A single disc prolapse was found in all cases, which occurred between T8 and T12. A history of trauma was obtained in $35 \%$, the injury occurring from 8 months to 18 years previously. The patients presented with a progressive myelopathy, 13 presenting with a history of less than 1 year and $95 \%$ within 2 years. Whilst a symmetrical cord lesion was usual, a Brown Séquard syndrome was not uncommon. Seven patients had associated abnormalities of micturition. All patients were investigated with plain $x$ rays of the thoracic spine, myelography and more recently, CT scan of the appropriate level and MRI scan. In the author's opinion, the MRI scan is the investigation of choice. Soft disc prolapse was found in 6 patients with calcified hard lesions in the remaining 14 . Six of these latter cases had penetrated through the posterior longitudinal ligament and in 3 , the dura was also penetrated. All patients had strut grafting across the cavitation of the vertebral body.

Following surgery, 13 patients returned to previous occupations and a further 6 were improved from their preoperative state. The remaining patient was ambulant but symptomatically unchanged.

The author concluded that the laminectomy approach should be discarded, with the anterolateral approach derived from costotransversectomy undoubtedly the approach of choice in elderly patients and in patients with lung disease. As the majority of disc prolapses occur between $\mathrm{T} 9$ and T12 vertebrae, the transthoracic approach at these levels frequently requires a thoracoabdominal procedure. 
THE PREDICTION OF FREE PROLAPSE IN LUMBAR DISC PATIENTS FROM THEIR CLINICAL PRESENTATION

IK Pople, HB Griffith. Bristol

Patients who present for lumbar discectomy with predominantly leg pain are known to have a better result. To assess whether this is related to the presence of free prolapse the relative proportions of back and leg pain were compared with operative findings in a prospective observational study. One hundred consecutive cases over 12 months were independently assessed (IP) without knowledge of the operative findings. The operating surgeon recorded either a free prolapse, or a subligamentous prolapse when discectomy necessitated incision or probing of the annulus or ligament.

Of the 58 men and 42 women (mean age 42 , range 19-75) in the study, 47 patients had a subligamentous prolapse and 53 had a free prolapse. Of 27 patients who presented with leg pain alone 26 (96\%) were found subsequently to have a free prolapse. Patients with a free prolapse had a significantly higher proportion of leg:back pain (median 99:1) than those with a sub-ligamentous prolapse (median 75:25, 2-sample median test, $\mathrm{p}<0.001)$. Thirty three of 39 $(85 \%)$ patients with predominantly leg pain $(>90: 10)$ had a free prolapse. The authors concluded that patients with leg pain alone and those with a marked predominance of leg pain over back pain have a high probability of harbouring a free prolapse and this explains their better outcome.

THE CERVICAL SPINAL LOCKING PLATE FOR ANTERIOR SURGERY.

F Johnston, A Crockard, M Powell. Queen Square, London

Although commonplace in modern neurosurgery, anterior approaches to the cervical spine are not uniformly successful; prevention of graft displacement and non-union in mobile subluxation, of kyphus development in multilevel spondylotic disease and the maintenance of normal bony alignment in complex spinal disorders remain the major challenges. Currently available stainless steel implants such as the Caspar plate have had some success in managing these problems obviating the need for a major orthosis, but the employment of bicortical screw fixation together with MRI incompatibility are major disadvantages. The authors reported their experience with a purposedesigned CT/MR compatible titanium cervical plate with cancellous locking screws in the management of such problems (Synthesis AO plates).

Twenty eight patients $(M=16, F=12)$ with a mean age of 55 years range (10-84 years) had undergone anterior spinal fixation extending from two to five vertebral bodies, using the plate and autogenous bone graft. Three patients had surgery for vertebral neoplasms and three for trauma, whilst the remaining 22 had degenerative arthritides and six of this group had symptomatic iatrogenic kyphoses due to previous laminectomy or anterior vertebral body or graft collapse. Satisfactory fixation and fusion was obtained in all patients except two, with no case of neurological deterioration. Specific complications included six cases of transient dysphagia, one of sepsis, one of Horner's syndrome; one patient had a fatal myocardial infarction the night after surgery. The authors recommended this form of anterior fixation.

A SURGICAL APPROACH TO THE MANAGEMENT OF RHEUMATOID DISEASE OF THE CERVICAL SPINE

RJ Laing, D Stanley, CJ Getty, DMC Forster. Sheffield

A significant proportion of patients with long standing erosive rheumatoid arthritis develop significant involvement of the cervical spine and up to $15 \%$ of these require surgery to prevent neurological deterioration or relieve intractable pain. Although operative treatment has been shown to be beneficial, the type and timing of surgery remains controversial. The authors reviewed their experience of the treatment of 47 rheumatoid patients with cervical spine disease during an eight year period from 1982-90. Thirty seven had a total of forty operations whilst ten either refused surgery or had minimal symptoms and signs of cervical spine disease and were treated conservatively. Posterior decompression and fusions were performed in twenty one patients, nine patients had anterior interbody fusions and seven patients had anterior and posterior decompression and fusion.

In the surgical group $70 \%$ were improved, $16 \%$ were unchanged and $14 \%$ died. The early mortality was $10 \%$, of which half was in patients aged seventy years or over. In the conservative group four patients died of unrelated causes and in the six long term survivors no patient suffered neurological deterioration. The importance of a solid bony fusion was discussed together with the value of early mobilisation in a Halo vest.

THE ROLE OF GADOLINIUM ENHANCED MRI IN THE INITIAL DIAGNOSIS AND FOLLOW UP OF INTRINSIC SPINAL CORD TUMOURS

\section{RJV Bartlett. Hull}

There is no reliable feature differentiating intramedullary ependymoma and astrocytoma. A recent publication ${ }^{1}$ suggests a hypointense pseudo-capsule or "cap" is specific for cervical ependymoma. From a large database of spinal tumours treated with radical laser surgery the MRI findings in 18 adult patients were reviewed retrospectively, including 5 astrocytomas and 5 ependymomas. Eight patients had multiple procedures. Images were assessed with particular attention to the pattern of gadolinium enhancement. All sequences were analysed for differentiation of tumour, oedema and cyst, post operative tethering, presence of haemorrhage and pseudocapsule formation. Observations were correlated with surgical findings. A "hypointense cap" was the only parameter helpful in distinguishing ependymoma and astrocytoma. Unfortunately, this feature was also present in a thoracic cavernous haemangioma and in a haemorrhagic "holo cord" astrocytoma, and hence was non specific.

Individual cases illustrated dramatic enhancement due to radiotherapy, which subsequently regressed; dramatic gadolinium enhancement 2 weeks after surgery for malignant astrocytoma which was entirely due to surgery and pial enhancement possibly due to preceding myelography; and the development of haemorrhagic tumour-lined cysts in a holo cord astrocytoma.

1 Nemoto $\mathrm{Y}$, Inone $\mathrm{Y}$, Tashiro $\mathrm{T}$, et al. Radiology 1992;182:793-6.

A SPECT STUDY OF BRAIN PERFUSION IN PATIENTS WITH UNILATERAL ACOUSTIC NEUROMAS

RH Lye, K O'Driscoll, T Testa, J Lloyd, R Ramsden. Manchester

Transtentorial diaschisis may occur in patients with cerebral tumour ${ }^{1}$ or cerebellar haemorrhage. ${ }^{2}$ The effect of acoustic neuromas on regional brain perfusion had been assessed using single photon emission computed tomography (SPECT). Fifteen patients with unilateral acoustic neuromas were given $500 \mathrm{MBq}$ of tracer ( ${ }^{99 m} \mathrm{Tc}-\mathrm{HM}$ PAO) by intravenous injection preoperatively and 3-7d postoperatively. Images obtained by SPECT under standard conditions were independently assessed by an observer unaware of the tumour site.

The maximum tumour diameter was $3 \cdot 0-5.5 \mathrm{~cm}$ in 4 patients. All showed reduced uptake of tracer, not only in the region of the tumour but also supratentorially in the anterior part of the ipsilateral cerebral cortex. Moreover, amongst these patients there was heterogeneous increase of tracer uptake in the contralateral cerebral (2 patients) and cerebellar ( 1 patient) hemispheres. Perfusion was normal in one patient with a $2.0 \mathrm{~cm}$ tumour. Surprisingly, one patient with a small $(1.0 \mathrm{~cm})$ acoustic neuroma showed reduced perfusion in both the cerebral and cerebellar hemispheres opposite the side of the tumour.

These results indicated that acoustic neuromas may affect perfusion of the brain within ipsilateral and contralateral supratentorial compartments. Considerable discussion ensued over methodological aspects of SPECT.

1 Kushner M, et al. Ann Neurol 1984;15: 425-34. $2 \underset{511-14 .}{\operatorname{Rousseaux}}$ M, Steinling M. Stroke 1992;23:

COMPUTER IMAGING OF CORTICAL

UMBELIIFERONE CLEARANCE FOR

ESTIMATING CEREBRAL BLOOD FLOW

PJ Kirkpatrick, RM Bucknall, P Naylor, A J

Strong. Maudsley Hospital, London

Computer imaging of the cortex during elution of a $\mathrm{pH}$ sensitive fluorescent dye has provided a non invasive means of estimating cerebral blood flow (CBF) with high temporal and topographical resolution. Under varying conditions of blood pressure and arterial blood gases, quantitative digitised images of the exposed cortex irradiated with ultraviolet light $(360-370 \mathrm{~nm})$ were grabbed at $15 \mathrm{~s}$ intervals after 1-2 mls of saturated umbelliferone solution were injected into the lingual or external carotid artery of anaesthetised cats and rabbits, respectively. Specific software (Impress) allowed both parenchymal regions of interest (ROIs) to be defined that were automatically transferred to sequential images, and also calculation of the initial slope equation for CBF from the exponential decay in grey level fluorescence. Further, by solving the equation on a pixel by pixel basis, a pseudocoloured cortical map of CBF could be generated. Clearances were rejected if the r-squared for 
regression was less than $90 \%$ as this indicated poor dye delivery or recirculation. Mean CBF values of 99.5 (95\% CI 89.4-110) $\mathrm{ml} / 100 \mathrm{~g} / \mathrm{min}$ were obtained for rabbits $\mathrm{N}=11$, mean $\mathrm{BP} 75$, mean $\mathrm{pCO}_{2}=33$, pO $=112)$; and $65 \cdot 1(95 \%$ CI $55-75) \mathrm{ml}$ $100 \mathrm{~g} / \mathrm{min}$ for cats $(\mathrm{N}=8$, mean $\mathrm{BP}=93$; $\left.\mathrm{pCO}_{2}=31.5 ; \mathrm{pO}_{2}=115\right)$. The method was reproducible, and sensitive to the cerebrovascular responses of autoregulation and $\mathrm{pCO}_{2}$ reactivity. Early experience indicates a potential use in the repeated monitoring of $\mathrm{rCBF}$ during ischaemia, and in the estimation of associated changes in ion homeostasis.

THE DOSE RESPONSE RELATIONSHIP AND THERAPEUTIC WINDOW FOR DIZOCILPINE (MK-801) IN A RAT FOCAL ISCHAEMIA MODEL RH Hatfield. Cambridge

The dose response relationship and the maximum time for which effective therapy could be delayed had been quantified for the N-methyl-D-aspartate antagonist dizocilpine (MK-801) as a neuroprotective agent in a permanent focal ischaemia model in the rat. The $\mathrm{ED}_{50}$ for dizocilpine in the amelioration of cortical damage in this model was found to be approximately 0.3 $\mathrm{mg} / \mathrm{kg}$ (single ip dose, 30 minutes post onset of ischaemia) and significant protection was only obtained when therapy $(3 \mathrm{mg} / \mathrm{kg}$, ip.) was delayed for one hour or less after the onset of ischaemia. Dizocilpine $3 \mathrm{mg} / \mathrm{kg}$, ip produced a peak plasma level of $44 \mathrm{ng} / \mathrm{ml}$ and had a $\mathrm{t} \frac{1}{2}$ elimination of 1.65 hours. These results confirmed the neuroprotective efficacy of dizocilpine in focal ischaemia but the therapeutic window for post ischaemic treatment was relatively short in this model.

BIOCHEMICAL CHANGES IN HYDROCEPHALUS AND SUBARACHNOID HAEMORRHAGE USING ${ }^{31}$ PHOSPHORUS MAGNETIC RESONANCE SPECTROSCOPY

NSR Brooke, R Ouwerkerk, CBT Adams, GK Radda, JGG Ledingham, RBR Rajagopalan. Oxford

Brain metabolism can be assessed using ${ }^{31}$ phosphorus magnetic resonance spectroscopy ( ${ }^{31} \mathrm{P} \mathrm{MRS}$ ). The intracellular $\mathrm{pH}$ (pHi) of 6 patients (age range 23-73) with symptomatic hydrocephalus was measured. Five patients had obstructive hydrocephalus, secondary to aqueduct stenosis (4) or acoustic neuroma(1). The sixth patient had communicating hydrocephalus of unknown cause. Raised ICP was confirmed by pressure monitoring. Both hemispheres were studied on each occasion and all patients underwent pre-operative ${ }^{31} \mathrm{P}$ MRS and 4 patients had between 1 and 3 post operative scans between 2 days and 3 months after shunting.

The normal range for cerebral $\mathrm{pHi}$ is $7 \cdot 05 \pm 0 \cdot 05$. Before shunting, reduced pHi was seen in 5 cases in one or both sides studied in the deep white matter. $\mathrm{pH}$ ranged from $6 \cdot 66-6 \cdot 98$. In 3 cases the 2 hemispheres showed different $\mathrm{pHi}$, one side being acidic, the other normal except in one case, where the pHi was alkaline $(7 \cdot 14)$ Post shunting, all patients clinically improved. Whereas a further decrease in $\mathrm{pHi}$ was seen in 2 patients in the first nine days after shunting, $\mathrm{pHi}$ was seen to lie within the normal range by between 6 and 12 weeks. One patient showed marked alkalinisation of $\mathrm{pHi}$ to values of 7-19. ${ }^{31} \mathrm{P} \mathrm{MRS}$ can thus detect changes in pHi secondary to raised ICP and its improvement by shunting.

Ten cases were studied on 30 occasions, at various times after SAH, using ${ }^{31} \mathrm{P}$ MRS Three cases were Grade 1 on admission and remained so. ${ }^{31} \mathrm{P}$ MRS showed normal $\mathrm{pHi}$ at all depths. Six cases, although Grade II on admission, deteriorated. Rebleeding and gross hydrocephalus were excluded by repeat CT in 4 cases. In 5 cases, ${ }^{31} \mathrm{P}$ MRS showed areas of acidosis ( $\mathrm{pHi}=6.54-6.9)$ between 3 and $6 \mathrm{~cm}$. In 4 cases undergoing sequential studies acidosis improved with time and clinical condition. One case was grade IV on admission (right hemiparesis and dysphasia). pHi was normal at all depths on 2 occasions at 3 and 7 days after $\mathrm{SAH}$. The reduced $\mathrm{pHi}$ observed in cases who develop decreased conscious level or focal neurology represents ischaemia Recovery of pre-morbid clinical condition and return of $\mathrm{pHi}$ to normal implies the process is reversible. ${ }^{31} \mathrm{P}$ MRS therefore provides a useful tool for studying cerebral ischaemia secondary to SAH and monitoring therapeutic intervention.

DELAYED CEREBRAL ISCHAEMIA: THE ROLE OF THE HYPOTHALAMUS AND DISTURBED SYSTEMIC AUTOREGULATION AFTER AN ANEURYSMAL SUBARACHNOID HAEMORRHAGE DA Lang, G Neil-Dwyer, A Doshi, CG Gerber, P Smith. Southampton

Cerebral ischaemia is a common cause of increased morbidity and mortality after an aneurysmal subarachnoid haemorrhage. Syndromes of cerebral ischaemia have been previously reported to relate to histological changes in the cerebral cortex and loss of systemic autoregulation may be the substrate of this pathology. Histological changes of ischaemia in the hypothalamus have been described after a subarachnoid haemorrhage and are associated with autonomic dysfunction. Hypothalamic lesions were found in 24 out of 48 patients who died after a subarachnoid haemorrhage and 23 of these patients had associated lesions in the cerebral cortex. Patients with moderate/severe cortical lesions tended to have hypothalamic lesions and it was uncommon for patients with no cortical lesions to have changes in the hypothalamus $(p=0.0012)$ Ischaemic hypothalamic lesions were also more frequent in patients with an unstable blood pressure $(p=0.05)$. These findings support the view that the hypothalamus may play an important role in the genesis of deranged cerebral autoregulation and delayed cerebral ischaemia after a subarachnoid haemorrhage.

1 Doshi R, Neil-Dwyer G. $\mathcal{f}$ Neurol Neurosurg Psychiatry 1988;51:466.

AUTOREGULATION AND THE TRANSIENT HYPERAEMIC RESPONSE (THRT) IN PATIENTS WITH SUBARACHNOID HAEMORRHAGE (SAH). V Iyer, $\mathbf{M}$ Czosnyka, $\mathbf{H}$ Whitehouse, PJ Kirkpatrick, JD Pickard. Cambridge

The risk of cerebral ischaemia following $\mathrm{SAH}$ is increased in patients with impaired autoregulation as assessed using radionuclides. ${ }^{1}$ Is it possible to use a simpler bedside technique based on transcrania doppler (TCD) to assess autoregulation in these patients? Theoretically the transient increase in middle cerebral artery (MCA) blood flow velocity (FV) after a brief common carotid compression (CCA) relates to whether autoregulation is intact. ${ }^{2}$

Bilateral MCA flow velocities and arterial blood pressure were monitored daily in 25 SAH patients before and after a 3 second compression of the CCA. A total of 386 complete measurements were made of flow velocity (FV), pulsatility index (PI) and THRT. There were 298 positive (P) and 88 negative (N) THRT responses.

A negative THRT was found to correlate with a poorer clinical grade (HUNT and HESS) $(P<0.025)$ and a worse Glasgow outcome $(P<0.021)$. The probability of a positive THRT appears to be lower as flow velocity increases and is least between day 6 and day 14 after a bleed when vasospasm is expected to occur. The THRT provides information additional to $\mathrm{FV}$ alone.

Pickard J D, Matheson M, Patterson J, Wyper D. F Neurosurg 1980;53:305-8.

2 Czosnyka M, Pickard J D, Whitehouse $H$, Piechnik S. Acta Neurochirurgica (Wien) 1992;115:90-97.

LE FORT MAXILLOTOMY FOR MIDLINE POSTERIOR CIRCULATION ANEURYSMS EXPERIENCE WITH TEN CASES WAS Taylor, D Uttley, DJ Archer. Atkinson Morley's Hospital and Royal Marsden Hospital, London

Aneurysms of the posterior cerebral circulation which lie in the midline in front of the neuraxis are relatively inaccessible surgically. Dissection around cranial nerves and retraction of the neuraxis is required which may result in significant morbidity. An anterior approach would avoid these problems by approaching the aneurysm directly. The authors used the Le Fort osteotomy and clivectomy to approach the anterior skull base to treat ten aneurysms.

All patients in this consecutive series presented with subarachnoid haemorrhage and at the time of surgery were WFNS grades I and II. This reflected the timing of surgery with the majority having delayed surgery. The sites of the aneurysms treated were six posterior inferior cerebellar aneurysms, two anterior inferior cerebellar aneurysms and two aneurysms at the vertebro-basilar junction. All of the aneurysms treated lay in the midline. Nine of the aneurysms were clipped and one of the aneurysms was wrapped with muslin. There was no surgical mortality and morbidity was one transien VIth nerve palsy and two cases of meningitis although there were no overt CSF leaks. Follow up was for at least six months in all cases and at six months all patients had achieved a good outcome on the Glasgow Outcome Scale.

This series suggests that this approach can be employed safely to treat these aneurysms but with the reservation that access is adequate for only true midline aneurysms. The approach is particularly useful for aneurysms which arise from the basilar trunk that are virtually inaccessible from the sub-occipital and supra-tentorial approaches. 
Titles of papers presented by members of the Deutsche Gesellschaft für Neurochirurgie

ARE MENINGIOMAS ENDOCRINE TUMOURS? R Fahlbusch, UMH Schrell. Erlangen

IN VIVO STUDIES OF THE ROLE OF ANGIOGENIC GROWTH FACTORS IN MALIGNANT BRAIN TUMOURS

MN Nemati, K Fryburg, A Stan, K-M Putz, GF Walter, H Dietz. Hannover

MINIMALLY INVASIVE ENDOSCOPIC INTERVENTIONS ON PROCESSES OF THE VENTRICULAR SYSTEM

D Hellwig, T Riegel, B L Bauer. Marburg

CLINICAL EXPERIENCE WITH VENTRICLE PUNCTURE FOR EXTERNAL CSF DRAINAGE AND PRESSURE MEASUREMENT USING A SPECIAL PUNCTURE NEEDLE E Behrens, J Zentner. Bonn
BRITISH/GERMAN MEDICAL RELATIONS IN HISTORICAL PERSPECTIVE

KA Bushe. Würburg

MANAGEMENT OF CHRONIC SUBDURAL HAEMATOMA BY TREPANATION AND DRAINAGE W Krupp, P Jans, R Müke. Essen

NIMODIPINE IN TREATMENT OF EXPERIMENTAL FOCAL CEREBRAL ISCHAEMIA H Wassmann, M Marinov, S Natschev. Sofia, Bulgaria and Munster

INDICATIONS FOR PERCUTANEOUS ENDOSCOPIC DISCECTOMY.

M Brock. Berlin

MULTILEVEL STENOSIS OF THE CERVICAL SPINAL CANAL

R Lorenz, D Rosenthal. Frankfurt

THE PREVENTION OF POSTLAMINECTOMY MEMBRANE BY FREE AUTOLOGOUS FAT GRAFTS

J Pospiech, R Kalff, F Pajonk, D Stolke, L Gerhard. Essen
INDICATIONS FOR EXTRACRANIAL-

INTRACRANIAL ARTERIAL BYPASS SURGERYFURTHER CONSIDERATIONS AND TRENDS IN GERMANY

HM Mehdorn. Kiel

ACUTE HYDROCEPHALUS AFTER

SUBARACHNOID HAEMORRHAGE: INCIDENCE AND RESULTS OF ITS TREATMENT IN POORGRADE PATIENTS

T Brinker, C Goetz, H Dietz. Hannover

TIMING AND GRADING IN POOR-GRADE SUBARACHNOID HAEMORRHAGE.

R Laumer, R Fahlbusch, R Naraghi, Ch Nimsky. Erlangen-Nürnberg

INFLUENCE OF EARLY AND LATE ANEURYSM SURGERY AND INTRAOPERATTVE HAEMORRHAGE RELATED TO HUNT AND HESS GRADES

J Schramm, C Cedzich, CH Hoffmann. Bonn 